\title{
THE INFLUENCE OF RESPIRATION ON VENOUS PRESSURE
}

\author{
By OVID O. MEYER AND WILLIAM S. MIDDLETON
}

(From the Department of Medicine, University of Wisconsin)

(Received for publication May 1, 1929)

The effects of the respiratory movements upon the circulation have seriously concerned physiologists and clinicians for many years. The classical experiments of Poiseuille (1) constitute the first substantial contribution to the knowledge of the influence of respiration upon the venous flow. The following quotations state his conclusions:

Ainsi, au moment de l'inspiration, l'air de la poitrine se raréfiant par la dilatation de cette cavité, la pression de l'atmosphère l'emporte, sur celle de l'air qui y est renfermé, et le sang des veines jugulaires tend à se précipiter dans le thorax; au contraire, dans l'expiration, la poitrine se resserrant, la pression de l'air intérieur devient plus grande, les veines sont comprimées, par suite le sang de ces vaisseaux reflue hors de la poitrine.

Ainsi, nous croyons devoir conclure qui si l'inspiration appelle vers la poitrine une certaine quantité de sang veineux, l'expiration aussi concourt puissamment à mouvoir le sang vers le coeur.

Nous concluons que l'aspiration due à la dilatation de la poitrine et à celle du côté droit du coeur n'est point lacause principale du mouvement du sang veineux, mais que par cette aspiration les gros troncs veineux se dèchargeant dans la poitrine, le sang veineux des autres veines trouve seulement moins de résistance à se mouvoir; cette cause n'est donc qu'accessoire et rien de plus.

A considerable literature has grown about this subject, but no worker has carried his studies to more exact conclusions than Poiseuille. One of his most important observations was the increase in the respiratory influence on the venous pressure as the thorax is approached. Burton-Opitz (2) by improved methods established a decrease in venous pressure from the periphery to the center of the circulation at the rate of $1 \mathrm{~mm}$. of mercury for each $35 \mathrm{~mm}$. distance. Negative pressure was first noted by him in the veins in close proximity to the 
thoracic cavity, and variations in the venous pressure dependent upon the respiratory movements were most marked here. The lowest pressures were recorded at the end of inspiration and the highest at the end of expiration. Burton-Opitz established a disappearance of the negative venous pressure even in the veins abutting the thoracic cavity, when the negative intrapleural pressure was relieved by a pneumothorax. By electropolygraphic methods Waud (3) noted the rise of the venous curve in the latter half of inspiration and its continuance into the beginning of expiration. The period of inertia into the expiratory phase constituted about two cardiac cycles.

Most authorities are apparently agreéd on the minor influence of the respiratory activity on the venous pressure in the small peripheral veins of normal individuals. Sewall (4) remarked that "the superficial veins of the extremities normally dilate and the pressure within them increases as result of inspiration. The respiratory movements of the veins correspond with the respiratory changes in arterial blood pressure." This phenomenon he attributed to the increased flow from the capillary bed, but ample evidence (5) (6) is available to disprove a direct relationship between either capillary or arterial blood pressure and venous pressure. Furthermore, Gottwald (7) adduced evidence that the venous pressure changes of respiration are independent of circulatory acceleration and apparently entirely dependent upon changes in the intrapleural negative pressure. Bedford and Wright (8), by the direct method of Claude, found no influence on the venous pressure (in the arm veins) of nor nal individuals on ordinary breathing. One-half to one $\mathrm{cm}$. of water variation was determined in certain pathologic cases.

Some difference of opinion exists in the question of the comparative figures for venous pressure changes in the upper and the lower extremities under the influence of respiration. Since the present studies deal only with venous pressure in the arm, the merits of the two sides of the question need not be discussed.

Disturbances of the respiratory rhythm reflect themselves very promptly in venous pressure changes. Bedford and Wright (8) recorded invariable rises in the venous pressure on holding a deep breath; for example, a normal pressure of $7 \mathrm{~cm}$. of water rose to $25 \mathrm{~cm}$. Conversely they noted falling venous pressures on over-ventilation. 
In the headdown position Henderson, Prince and Haggard (9) established a fall of from 8 to $11 \mathrm{~cm}$. of venous pressure in six normal subjects on voluntary hyperpnoea, the values reaching the negative level. They attributed this fall to the decreased carbon dioxide content of the blood. In their opinion, carbon dioxide is an active veno-pressor agent. Kroetz (10), likewise, corroborated the constant fall in venous pressure on over-ventilation. His figures 0.7 to $2.5 \mathrm{~cm}$., represent the slightest decrease recorded and he furthermore noted that this fall occurred within the first 20 seconds of the exercise.

These physiologic observations of the influence of respiration upon the venous pressure suggest many points of clinical application. Occasion (5) has been taken to report the virtual pathognomonic value of venous pressure readings in cardiac decompensation and the conclusion has been drawn that "excluding local causes of venous obstruction, abnormal venous pressures invariably mean cardiac failure, independent of the cause of failure or the associated disease." Added experience in the study of the venous pressure in respiratory diseases of the nature of lobar pneumonia confirms the conclusion above drawn. Contrary to Kroetz's experience (10) bronchial asthma per se in the interval between attacks induced no elevation of the venous pressure in a series of 11 cases, 8 of whom were emphysematous. An additional group of 5 cases of emphysema fro $n$ causes other than bronchial asthma likewise failed to exceed the normal limit of $11 \mathrm{~cm}$. of water venous pressure. The figures for this group ranged from 5 to $11 \mathrm{~cm}$. of water. During the asthmatic seizures the venous pressure rises precipitously and is maintained at high levels; as witnesses a case of this series in whom the venous pressure mounted from 11 to $23 \mathrm{~cm}$. of water during a severe attack which lasted $2 \frac{1}{2}$ hours. An extreme case of pneumoconiosis, terminating fatally, showed venous pressure readings between 14 and $16 \mathrm{~cm}$. of water, and at necropsy presented a clear picture of right heart failure succeeding compensatory right sided hypertrophy. Four cases of pneumoconiosis without signs of myocardial involvement showed no rise of venous pressure.

Turning to disturbances of the respiratory rhythm the possible influence of Cheyne-Stokes' respiration on the venous pressure suggested itself. Burger (11) has shown plethysmographic changes of a rhythmic order in Cheyne-Stokes' respiration. Accordingly venous pres- 
sure changes might be anticipated. Twenty-two observations have been made on 18 patients with this disturbance of the respiratory rhythm. The elevation of the venous pressure during the apnoeic period has been invariable, as has also been the fall from this high level during the succeeding hyperpnoea. The average difference in the venous pressure readings of the apnoeic and the hypernoeic periods was $6 \mathrm{~cm}$. of water in this group of cases. The greatest fluctuation occurred in a cardio-renal patient, whose venous pressure registered 28 $\mathrm{cm}$. of water in apnoea and $16 \mathrm{~cm}$. in the hyperpnoeic period. While the duration of the apnoea and the degree of hyperpnoea apparently exerted considerable influence in determining the variations in a given individual, it is important to note that no rule could be formulated for an average response under similar conditions in a second subect.

Significant changes in the venous pressure likewise occur under the conditions of general anaesthesia. Meyer and Middleton (12) have collected data establishing a virtually constant rise of venous pressure during induction, which they attribute to the disturbed respiratory rhythm, muscular effort and possibly an elevated carbon dioxide content of the blood. Thereafter the venous pressure falls to a plateau, usually somewhat above the normal for the subject, and maintains this level, except for periods of muscular activity or altered respiration, throughout the anaesthesia.

Certain physiologic acts, as defecation, parturition, coitus, coughing, and lifting, or occupations, as glass-blowing, playing wind instruments and the like, constitute an interesting problem from the circulatory standpoint. The following episode is not unusual:

E, H., a white male, 64 years of age, laborer by occupation, was admitted to the Bradley Memorial Hospital on December 7, 1920, complaining of shortness of breath. Precordial distress had developed on effort about a year previously and succeeding this experience dyspnoea became increasingly evident on slight strain. About six months after the onset, oedema appeared in the extremities and later the abdomen bloated.

The past medical history offered scarlet fever as the only suggestive etiologic background. The occupation of laborer had been changed to painter within the past $4 \frac{1}{2}$ years. Otherwise the social and family histories were irrelevant.

Physical examination established the existence of marked cardiac decompensation with emphysema, pulmonary oedema, relative mitral insufficiency, and general arteriosclerosis. Under bed rest and digitalis therapy the passive congestion 
of the lungs, general anasarca and subjective condition of the patient improved for a time; but on the 31st day after admission the venous pressure which had gradually advanced from $6 \mathrm{~cm}$. of water to $11 \mathrm{~cm}$., sharply rose to $20 \mathrm{~cm}$. Coincidently the oedema of the lungs increased and the liver was palpable $5 \mathrm{~cm}$. below the costal margin in the right midclavicular line. The patient became cyanotic and dyspnoea was profound. Accordingly $400 \mathrm{cc}$. of blood was let and the venous pressure fell to $5 \mathrm{~cm}$. with corresponding improvement in the subjective and objective evidences of right heart failure. Within the next two days the venous pressure had stabilized at $8 \mathrm{~cm}$. and the general and circulatory conditions were satisfactory.

Thereafter the circulatory balance fluctuated and the venous pressure ranged from 8 to $16 \mathrm{~cm}$. However, on the 8 th day after venesection the venous pressure was read at $8 \mathrm{~cm}$. and there were fewer basal râles. In the afternoon the patient was helped to a commode, had an evacuation of the bowels and fell to the floor dead.

So-called "bed pan" deaths are relatively common occurrences in large general hospitals dealing with great numbers of cardio-vascular cases. In effect, the effort represented by defecation and the other circumstances listed constitutes a Valsalva experiment, a forced expiratory effort with the glottis closed. Dawson and Hodges (13) have thoroughly analyzed the situation from the standpoint of the arterial hemodynamics. Moritz and v. Tabora (14) and Burger (11) have recorded marked rises in the venous pressure under the Valsalva experiment to $42 \mathrm{~cm}$. and $50 \mathrm{~cm}$. of water respectively. Kroetz (10) similarly obtained a figure of $40 \mathrm{~cm}$. Mosler and Balsamoff (15) made extensive observations on this phenomenon and suggested its use as a measure of cardiac tonus. They voiced the obvious necessity of avoiding such strain, when possible, in the cardiac cripple. On the other hand, Schott (16) suggested measurements of the venous pressure under the circumstance of a static effort, raising the leg, as a guide to the circulatory efficiency. He established a definite parallelism between the venous pressure curve and the ability of the heart to meet this static test. If this were true, it seemed even more logical to employ a dynamic test to establish the myocardial integrity.

First of all in order to standardize the procedure the indirect method of Hooker and Eyster (17) for the venous pressure determinations was routinely applied to subjects in the recumbent position. The subject was carefully instructed in the technique and the design of the Valsalva test, being particularly cautioned after taking a deep inspiration to 
exert as great an expiratory effort for as long a period as possible. One hundred and two tests were made on 51 normal subjects. The readings were taken at as frequent intervals as possible during the period of strain, and an assistant with a stop-watch recorded the time of these observations. The results were constant in the steady advance of the venous pressure through the period of effort. The curve

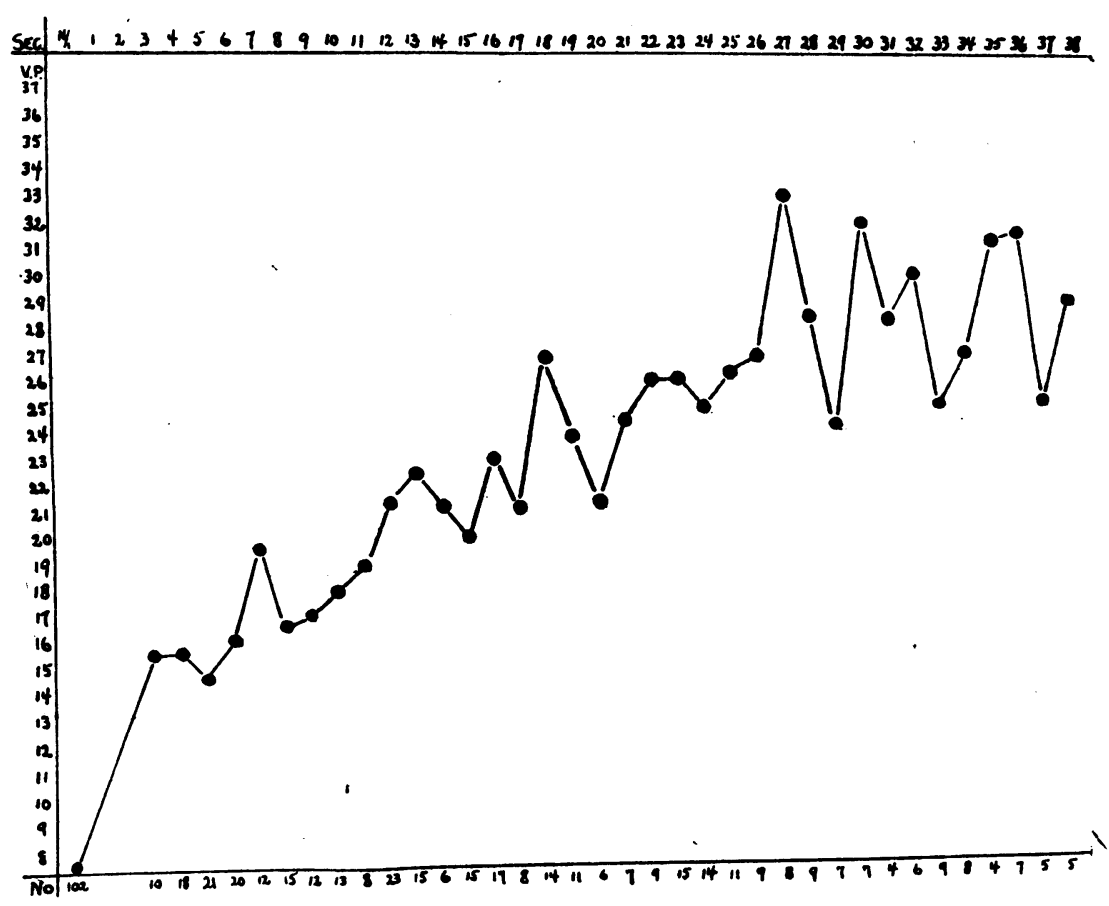

Fig. 1. Mean Curve of. Venous Pressure Response of 51 Normal Subjects To the Valsalva EXPERTMent

(No. indicates observations made at various time intervals)

(fig. 1) of the mean pressure for the several seconds is misleading in indicating fluctuations, but the general upward tendency to the twenty-eighth second will convey a fair impression of the curve of the average individual. After this period the number of subjects and their wide variance in pressure levels render the mean curve useless. It will be noted that the greatest single increment or percentage rise 
is in the first three seconds of the Valsalva. In figure $2 \mathrm{a}$ single normal individual has been selected at random and the curve of his venous pressure response to the Valsalva experiment plotted against the averages (of figure 1) for the same time intervals. A close coincidence of the curves will be remarked up to 27 seconds when the two diverge.

Naturally there is a wide individual variation in the duration and

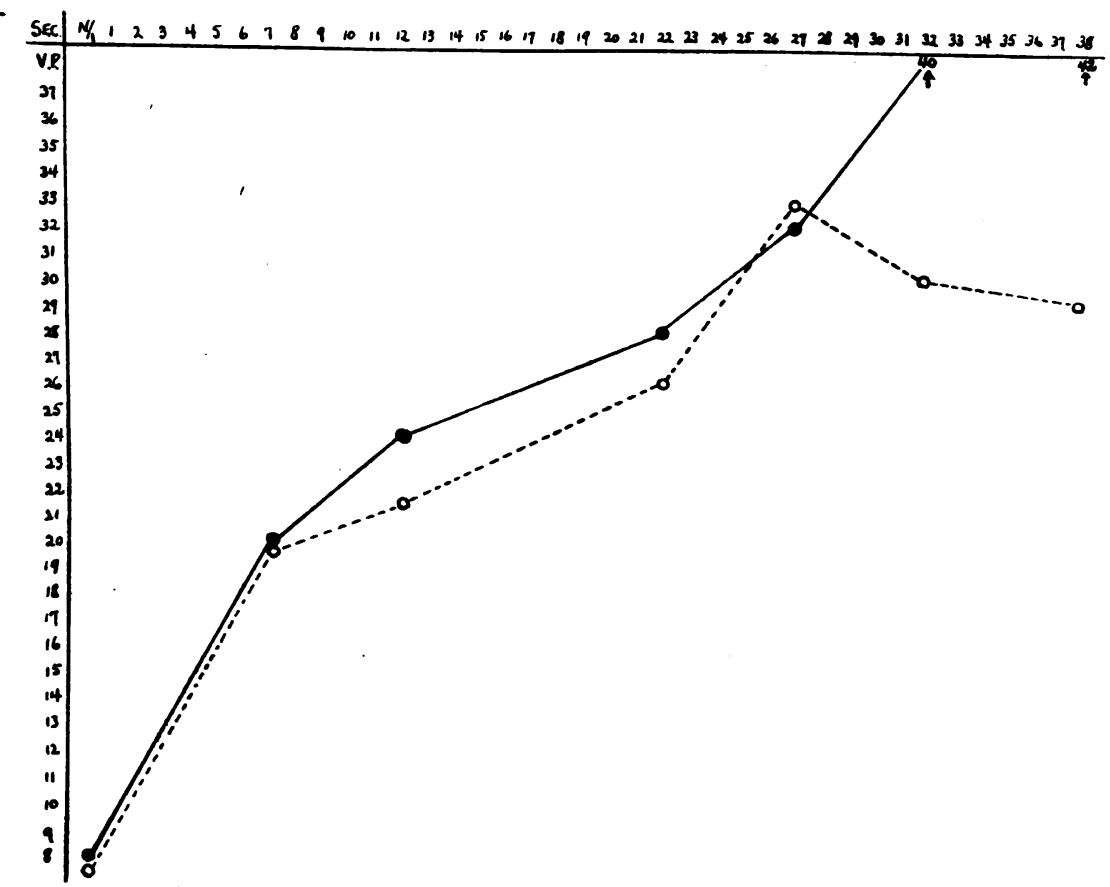

Fig. 2. Curve of Venous Pressure Response of a Single Normal Subject to the Valsalva Experiment (solid line) as Compared With Normal Mean (BROKen LINE)

the force of the expiratory effort. Failure of the subject to maintain the expiratory effort (or 'leak' as it came to be termed) is readily detected in the failure of the venous pressure curve to continue its rise. However, 48 of the 51 normal controls continued the effort for over 20 seconds. The majority of the group (31) maintained the expiratory effort for from 20 to 35 seconds and 17 exceeded 35 seconds. From a normal level of $7.6 \mathrm{~cm}$. of water only 4 individuals failed to exceed a 
venous pressure of $20 \mathrm{~cm}$. of water in their forced expiratory effort. The great majority (44) ranged between 20 and $40 \mathrm{~cm}$. venous pressure at the height of their effort and 3 exceeded $45 \mathrm{~cm}$. One of this high group of 3 responded unusually in levels of 50, 52, 50 and $52 \mathrm{~cm}$.

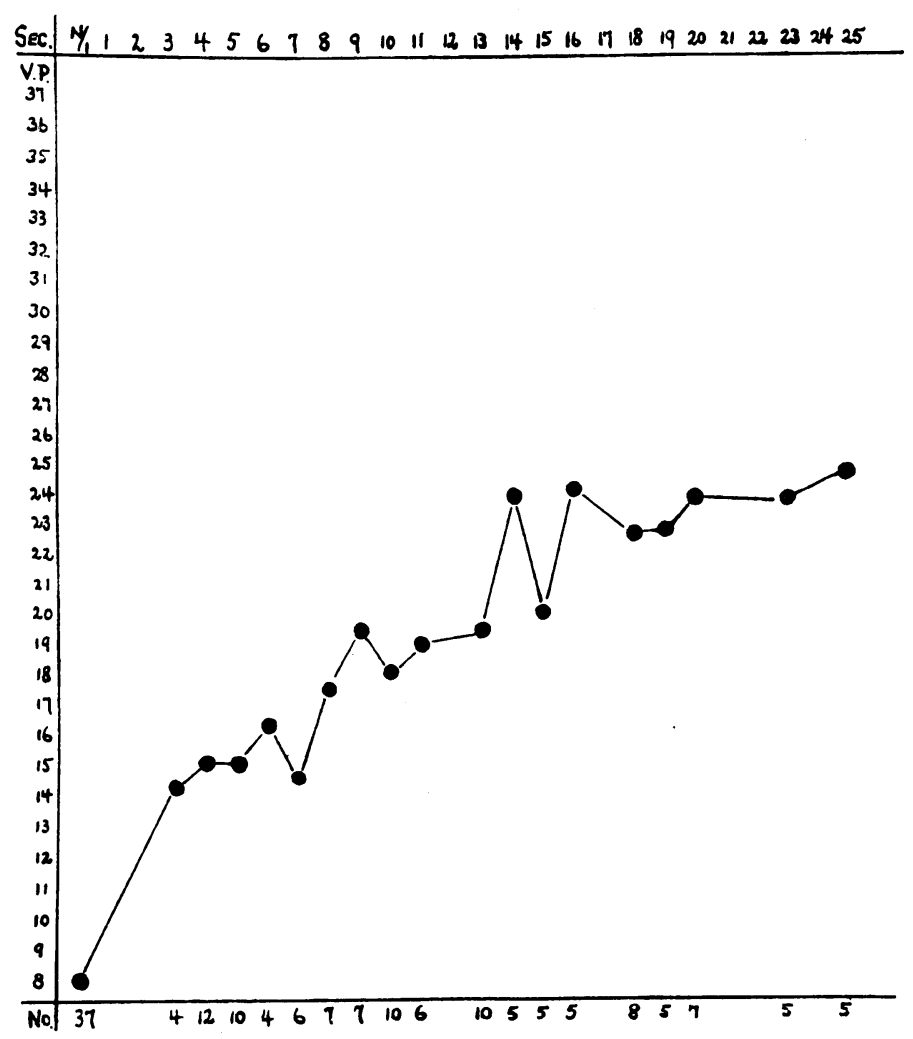

Fig. 3. Mean Curve of Venous Pressure Response of 31 Normal Subjects TO MÜLLER EXPERIMENT

(No. indicates observations made at various time intervals)

of water venous pressure, respectively, on each of four successive trials, maintaining the effort for 18, 28, 24 and 26 seconds for the corresponding tests. An intervening rest of 2-3 minutes elapsed between the several tests. Only one other normal individual approximated this level $(50 \mathrm{~cm}$. of water after 30 seconds of the Valsalva test). 
Repetition of this expiratory effort apparently developed an increased capacity in certain individuals, in that of 51 repeated observations 3 exceeded 55 seconds of strain. However, the figures for the remaining time intervals are comparable between single and repeated trials. Again the majority of the tests (45) showed a response of venous pressure to between 20 and $40 \mathrm{~cm}$. of water. Four Valsalva responses ranged from 40 to $52 \mathrm{~cm}$., including the three figures given in the last paragraph as repeated observations on an individual whose first reaction was high. While the data stated do not confir $n$ the impression, it is felt that, as a rule, repetition of the Valsalva effort at short intervals tends to cause increasingly higher response curves of venous pressure in a given individual.

The Müller experiment of a resisted inspiratory effort with the chest in the expiratory position was investigated with relation to its influence upon the venous pressure. Burger (11) and Kroetz (10) reported a constant fall to $4-5 \mathrm{~cm}$. and $2.5 \mathrm{~cm}$. of water, respectively. Thirty-seven observations were made on 31 individuals and the resultant mean curve (fig. 3 ) has been plotted from the figures for the several seconds. The greatest increment of increase in venous pressure occurs in the first 3 seconds as in the Valsalva experiment. Neither the primary rise nor the ultimate peak is as high as in the Valsalva. Without exception the individual curves show a constant upward tendency, and again seem dependent in a measure upon the duration and the force of the effort. The highest venous pressure of $50 \mathrm{~cm}$. of water was recorded after 24 seconds of effort and significantly he was the same subject in whom four unusually high responses to the Valsalva were noted above. No explanation has been found for the discrepancy between these results and those reported by Burger and Kroetz; and it is merely affirmed that, in the present studies, venous pressure readings were made from the time of initiation of the inspiratory effort with the chest in the expiratory position. In no instance was there determined a fall in the venous pressure during the continuance of the effort.

Since the venous pressure serves as a measure of right heart load (5), the estimation of the myocardial reserve through some dynamic test such as the Valsalva or the Müller seemed feasible. These tests of strain took precedence over the static tests such as utilized by 
Schott (16) by reason of the difference in the load represented and accordingly the greater venous pressure responses to be anticipated therefrom. At the same time the dynamic tests have the obvious disadvantage of a greater individual variation in the effort expended. The Valsalva experiment was used in preference to the Müller, be-

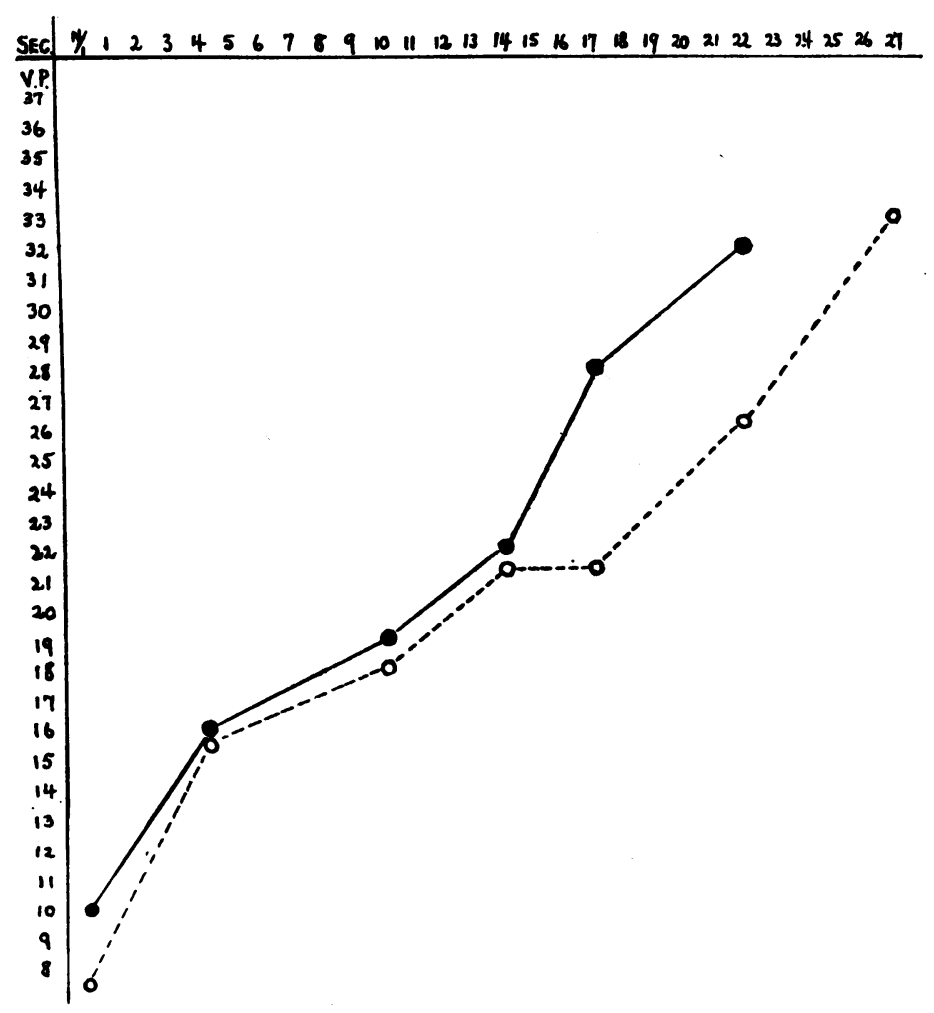

Fig. 4. Curve of Venous Pressure Response to Valsalva Experiment in Fully Compensated Hypertensive Patient (solid line) As Compared With Normal Mean (BRoKen LINE)

cause it is a more natural procedure. Instruction is simple and for a given normal individual the response within reasonable limits is relatively constant.

The realization of the strain implied in the test led to the greatest care in the choice of cardio-vascular subjects. At first only completely 
compensated cases were studied, and their response as typified by figure 4 , taken from a hypertensive subject with cardiac hypertrophy, coincides closely with the normal mean. On the other hand two types of response occurred where evidences of myocardial insufficiency were slight but apparent. In the first, as characterized by figure 5 ,

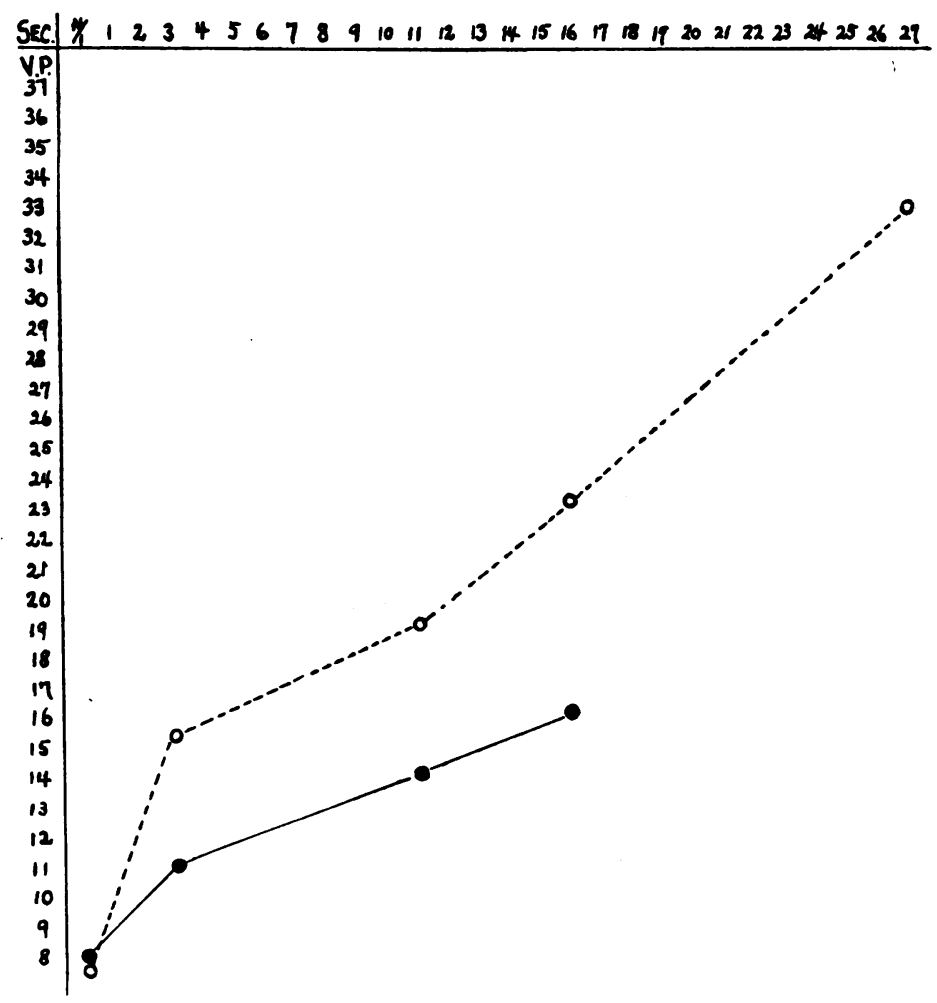

Fig. 5. Curve of Venous Pressure Response to Valsalya Experiment in Partially Compensated Cardiac Patient (solid line) as Compared With Normal Mean (Broken line)

there resulted a very inadequate response to the effort which was maintained for a very short period. In figure 6 there is represented the response in an individual, whose basic venous pressure before the test was constantly elevated, and who showed other evidences of right heart inadequacy. Under the Valsalva the venous pressure rise was 
prompt but not comparable in degree to the normal primary response and the levels for the period of strain were above the corresponding means. However, the effort was continued for a much shorter period than the average. It may be hypothesized that nature protects such individuals against right heart strain of this order by limiting the time over which the effort may be sustained.

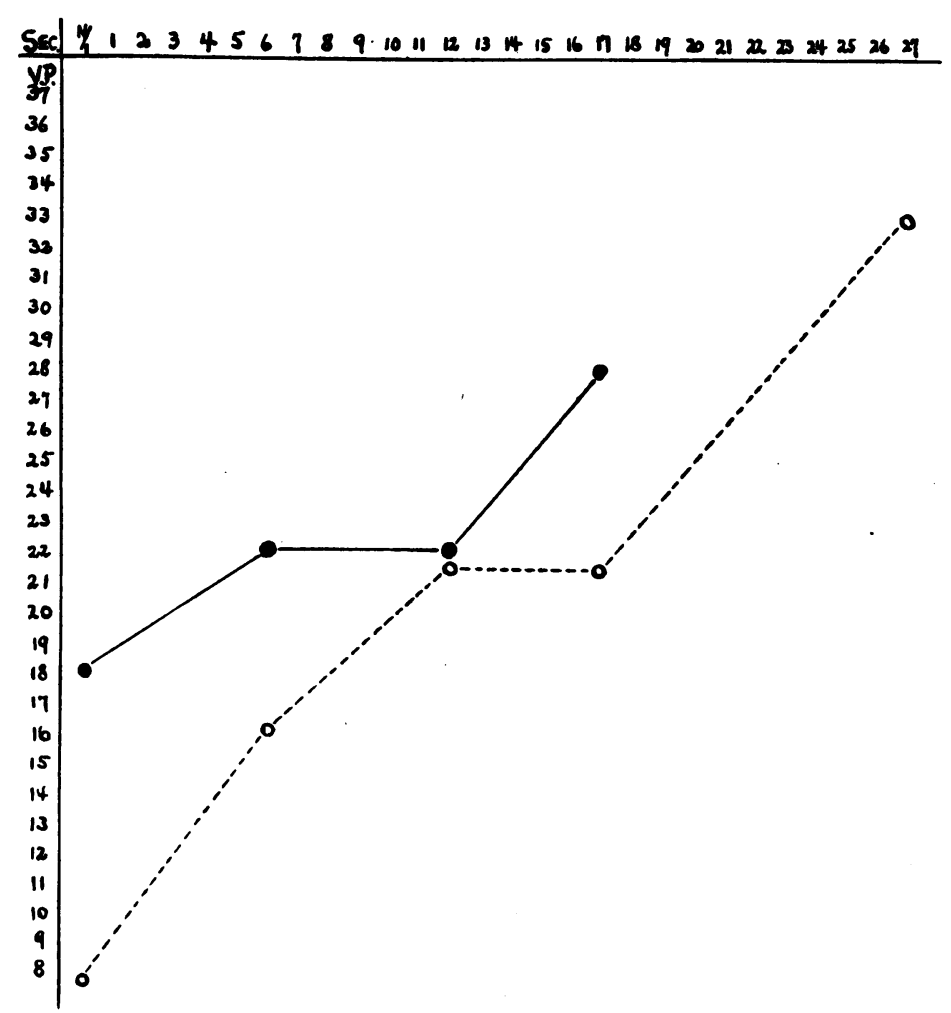

Fig. 6. Curve of Venous Pressure Response in Partially Compensated Cardiac Patient (solid line) as Compared with Normal Mean (BROKEN LINE)-VALSALVA Test

\section{CONCLUSIONS}

1. The respiratory influence on the venous pressure is considerable and reflects itself in certain clinical conditions. 
2. Marked venous hypertension is noted during attacks of bronchial asthma; but in the interval between the attacks the venous pressure is unaltered, provided the myocardium be intact.

3 . Venous pressure is elevated in the apnoeic period of CheyneStokes' respiration and falls during the hyperpnoea, regardless of the basic level of the venous pressure.

4. Anaesthesia is attended by significant rises of venous pressure during induction and by a fall to a plateau somewhat elevated above the normal for the subject through the anaesthetic period.

5. Great rises in venous pressure are found during the performance of the Müller and the Valsalva experiments. These changes may contribute to the fatalities in cardio-vascular patients under effort such as defecation, parturition and the like, which closely approximate the conditions of the Valsalva test.

6. As a test of right heart efficiency such methods must have a very limited field of usefulness on account of the too serious risk involved. It is possible that the venous pressure responses to the Valsalva test may give some prognostic information in the borderline case or some idea of the return of myocardial efficiency in the case followed through convalescence from a period of decompensation.

\section{BIBLIOGRAPHY}

1. Poiseuille, J. L. M., J. de Physiol. Exp. et Patholog. 1830, x, 277. Recherches sur les Causes du Mouvement du Sang dans les Veines.

2. Burton-Opitz, R., Am. J. Physiol., 1903, ix, 198. Venous Pressures.

3. Waud, R. A., Am. J. Physiol., 1924, lxxi, 112. The Effect of Respiration on the Venous Pulse as Studied by the Electropolygraph.

4. Sewall, H., J. Am. Med. Assoc., 1906, xlvii, 1279. Experiments on Venous Blood Pressure and Its Relation to Arterial Pressure in Man.

5. Eyster, J. A. E., and Middleton, W. S., Arch. Int: Med., 1924, xxxiv, 228. Clinical Studies on Venous Pressure.

6. Eyster, J. A. E., Physiol. Rev., 1926, vi, 281. Venous Pressure and its Clinical Applications.

7. Gottwald, E., Pfluger's Arch f. d. Ges. Physiol., 1881, xxv, 1. Der Normale Venenpuls.

8. Bedford, D. E., and Wright, S., Lancet, 1924, ccvii, 106. Observations on the Venous Pressure in Normal Individuals.

9. Henderson, Y., Prince, A. L., and Haggard, H. W., J. Pharmacol. and Exp. Therap., 1918, xi, 203. The influence of Forced Breathing upon the Circulation. 
10. Kroetz, C., Deutsch. Arch. f. klin. Med., 1922, cxxxix, 325. Die Koeffizienten des klinisch messbaren Venendruckes.

11. Burger, Munch. Med. Wchnschr., 1921, lxviii, 1066. Ueber die klinische Bedeutung des Valsalvashen Versuches.

12. Meyer, Ovid O., and Middleton, William S., Unpublished. The Venous Pressure in Anaesthesia.

13 Dawson, P. M., and Hodges, P. C., Am. J. Physiol., 1920, 1, 481. CardioVascular Reaction in the Valsalva Experiment and in Lifting with a Note on Parturition.

14. Moritz, F., and v. Tabora, D., Deutsch. Arch. f. klin. Med. 1910, xcviii, 475. Ǔber eine Methode beim Menchen den Druck in oberflächlichen Venen exakt zu bestimmen.

15. Mosler, E., and Balsamoff, Klin. Wchnschr., Berlin, 1924, iii, 491. Úber den Valsalva-Versuch.

16. Schott, E., Deutsch. Arch. f. klin. Med., 1912, cviii, 537. Die Erhöhung des Drucks im venösen System bei Anstrengung als Mass für die Functionstuchtigkeit des Menschlichen Herzens.

17. Hooker, D. R., and Eyster, J. A. E., Bull. Johns Hopkins Hosp., 1908, xix, 274. An Instrument for the Determination of Venous Pressure in Man. 